\title{
"Entre confianza y armas". La justicia local en Ecuador del Antiguo Régimen al liberalismo ${ }^{1}$
}

\author{
Federica Morelli \\ Universidad de Turín \\ federica.morelli@unito.it
}

Recepción: 2 de marzo de 2011 / Revisión: 15 de marzo de 2011

Aceptación: 19 de mayo de 2011 / Publicación: diciembre de 2011

\begin{abstract}
RESUMEN
El ensayo aborda el tema de la administración de justicia, especialmente de la justicia local, en el Ecuador entre Antiguo Régimen y liberalismo. Afirma que los problemas de la justicia sufridos por los ciudadanos durante las primeras décadas republicanas fueron el resultado de tres factores: 1) el papel de los cabildos coloniales americanos como instituciones a la vez judiciales y de gobierno; 2) los caracteres del liberalismo gaditano -e hispánico más en general- que no cambia la idea de justicia y que además confirma la naturaleza judicial de los municipios contribuyendo a su multiplicación en el territorio; 3 ) el papel de las guerras y la transformación de muchos jueces locales en milicianos. Así, de un modelo basado en la confianza en las calidades de las personas se pasa a otro basado en las armas.
\end{abstract}

Palabras clave: Justicia, jueces locales, antiguo régimen, liberalismo, cabildos, guerras, milicias, Ecuador, siglo XIX.

\section{"Between Confidence and Arms". Local Justice in Ecuador from the Old Regime to Liberalism}

\begin{abstract}
This essay deals with the administration of justice, and especially local justice, in Ecuador between the Old Regime and Liberalism. It claims that the judicial problems suffered by citizens during the first republican decades were the consequence of three major factors: 1) the role of colonial municipalities as legal and governmental institutions at the same time; 2) the character of Cadiz liberalism -and more generally Hispanic liberalism-, which did not change the idea of justice, confirming the legal nature of municipalities and furthermore increasing their number in the territory; 3 ) the role of the wars of independence and the transformation of many local judges into militiamen. Thus, from a model based on confidence in personal qualities, local justice changed toward a model based on arms.
\end{abstract}

Keywords: Justice, Local Judges, Old Regime, Liberalism, Municipalities, Wars, Militia, Ecuador, $19^{\text {th }}$ Century.

SUMARIO: 1. La naturaleza de los cabildos americanos. 2. La justicia gaditana: la convivencia de órdenes contradictorios. 3. La crisis del territorio urbano: la multiplicación de los municipios. 4. La guerra socializada: pueblos y milicias. 5. Referencias bibliográficas.

No habiendo en el seno del cantón hombres capaces de guiar los ciudadanos por el camino de la ley o de los principios sociales de justicia, sufren embarazos que aniquilan su reposo y fortuna. No hay jueces ni consultores, sin que los Alcaldes en la misma oscuridad de los litigantes deciden a su arbitrio de los intereses y del

${ }^{1}$ Este texto se inserta en el Proyecto I+D HAR2010-11580. 
honor ajenos [...] Muchas veces un hombre inocente se mira preso en la cárcel de un cantón, victima del odio del corregidor, del alcalde, del teniente o del hacendado, ¿por qué todos en los pueblos tienen jurisdicción?

Conciliador del Azuay, 12 de mayo de 1835

En 1835, cinco años después de la formación de la República de Ecuador y trece desde la independencia de España, un ciudadano de Cuenca exponía ante las autoridades estatales y la opinión pública de su ciudad una dramática pregunta con la que ponía en evidencia las dificultades del nuevo Estado para construir una justicia republicana: "¿por qué todos en los pueblos tienen jurisdicción?”.

Este interrogante percibe y subraya uno de los rasgos fundamentales de los regímenes independientes de Hispanoamérica durante el siglo XIX. No solo está referido a formas de control social - como la coacción o la corrupción- o con la persistencia de prácticas e instituciones de antiguo régimen, sino con algo mucho más arraigado en la mentalidad colectiva del mundo hispánico: una cultura jurídica que, teniendo el antiguo mundo corporativo y fragmentado como base, contribuía a reproducirlo. Sin embargo, para comprender los mecanismos que reprodujeron ese sistema jurídico hay que considerar tanto la herencia colonial, como la crisis de la monarquía, que acentuó algunas tensiones y creó otras. El abordaje del funcionamiento de la justicia local requiere considerar tres elementos: primero, el papel de los cabildos coloniales americanos como instituciones a la vez judiciales y de gobierno; segundo, los caracteres del liberalismo gaditano -e hispánico más en general- que no varía la idea de justicia y que, además, confirma la naturaleza judicial de los municipios contribuyendo a su multiplicación en el territorio; y, tercero, el papel de las guerras y la transformación de muchos jueces locales en milicianos.

\section{LA NATURALEZA DE LOS CABILDOS AMERICANOS}

La importancia de los cabildos coloniales en la estructuración del territorio americano ha sido muy estudiada por la historiografía. En contraste con otras áreas europeas, la dimensión municipal adquiere en Hispanoamérica más importancia debido a la ausencia de órganos representativos de los reinos. A esa prevalencia se suma que el cabildo fue una institución de autonomía local tanto de la sociedad blanca o criolla (los cabildos de españoles) como de la sociedad indígena (los cabildos de indígenas). Respecto a este grupo, la historiografía de los últimos veinte años ha demostrado ampliamente cómo esta institución de origen europeo fue manejada por la población india para redefinir su identidad a partir del nuevo escenario que implicó la conquista $^{2}$. Estas comunidades gozaban de personalidad jurídica y ejercían importantes funciones jurisdiccionales sobre el territorio y no es casualidad que, aún al final del siglo XVIII, se siguiera utilizando el término res pública, no tanto para indicar una

\footnotetext{
${ }^{2}$ Véase, por ejemplo FARris, 1984 y POLONI-Simard, 2000.
} 
entidad política superior, sino como atributo de las communitas, correspondientes a los cabildos ('república de españoles' y 'república de indios').

La ausencia de asambleas representativas y el papel desempeñado por las ciudades en la estructuración y organización del espacio nos han llevado a considerar a los cabildos como los cuerpos intermedios de la tradición hispanoamericana ${ }^{3}$. En primer lugar, porque habiéndose atribuido desde un inicio a las ciudades americanas las mismas características del sistema municipal peninsular, a los cabildos del Nuevo Mundo se les reconocieron amplios poderes jurisdiccionales sobre el territorio y la facultad de elegir sus propios jueces (alcaldes). La extensión de la jurisdicción territorial se modificó en el curso de la época colonial. Mientras que, inmediatamente después de la conquista, fue muy amplio a causa de la escasa población española, de la inmensidad de los territorios conquistados y del poco conocimiento de ellos, en los siglos XVII y XVIII su tamaño fue progresivamente reducido por la fundación de nuevas ciudades y por la exigencia de crear un número más elevado de distritos jurisdiccionales. En segundo lugar, otro elemento que permite identificar a los cabildos como los cuerpos intermedios de los reinos americanos fue la naturaleza hereditaria y electiva de sus cargos. Como subraya Montesquieu, la venalidad de los cargos y la elección de los miembros hacían del cabildo un órgano independiente del poder monárquico y, por tanto, un cuerpo intermedio. Y, en tercer lugar, el concepto de representación virtual del territorio vincula a los cabildos americanos con los cuerpos intermedios. Las ciudades americanas constituían los únicos sujetos del territorio que gozaban del derecho de representación frente al rey. Gracias al mismo, los municipios citadinos eran los representantes de un territorio que desbordaba los límites del espacio urbano, incluyendo una serie de pueblos y villas. A este respecto, cabe decir que si, por un lado, la extensión del territorio municipal diferenciaba la ciudad latinoamericana de la europea, por otro, igualaba aún más a los cabildos con los cuerpos intermedios europeos -parlamentos o estados provinciales. Como el ámbito municipal indiano correspondía a menudo con el de una provincia o de un reino europeo, los cabildos americanos podían considerarse verdaderas instituciones representativas del reino o de la provincia.

La fuerza de la representación territorial urbana fue la consecuencia del neto rechazo de la Corona a reconocer derechos políticos a los espacios rurales tras la conquista. Mientras el espacio político europeo se estructuró sobre la base de un dualismo entre la ciudad y el campo, titulares los dos de derechos políticos soberanos, el espacio americano se estructuró entorno a los cabildos, las únicas instituciones que gozaban de un derecho de representación frente al rey. La imposibilidad de acceder a derechos políticos fuera del espacio urbano, así como el mecanismo de venalidad

\footnotetext{
${ }^{3}$ Según la experiencia constitucionalista europea, se trataba de cuerpos que, nacidos como órganos judiciales para controlar la conformidad de los actos del soberano con las leyes fundamentales del reino (la monarquía limitada de origen medieval), terminaron por desarrollar importantes funciones jurisdiccionales que, de hecho, limitaron la acción del monarca. No eran nombrados directamente por el rey, sino que representaban a la sociedad y por esto tenían el deber de salvaguardar las leyes fundamentales del reino. Sobre la comparación entre los municipios americanos y los cuerpos intermedios de la tradición constitucionalista europea, véase MorelLi, 2005, pp. 191-194.
} 
de los cargos -que permitió a los hacendados articular poder social y poder público-, contribuyeron a hacer de la ciudad la representante de los intereses rurales. Los cabildos, cuya jurisdicción sobrepasaba los límites del área urbana, no se identificaban, así, exclusivamente con los intereses de esta última, sino, como fue evidente durante la crisis de la monarquía, se consideraban como los representantes de una "agrourban polis" soberana frente al Estado. Otra consecuencia de la institucionalización fallida del poder de los terratenientes fue que el espacio urbano se convirtió en el punto de mayor tensión estructural entre la Corona y los criollos, entorno al cual se afrontaron, durante toda la época colonial, dos tendencias opuestas: la voluntad de la Corona de convertir a la ciudad en el núcleo central del poder real y el deseo de los criollos de hacer de ella el centro de su poder. Esta tensión se hizo muy evidente durante la época del reformismo absolutista de la segunda mitad del XVIII, cuando los Borbones trataron de limitar las formas de autonomía corporativa de los territorios americanos. Sin embargo, su esfuerzo centralizador no logró romper los poderes jurisdiccionales de los municipios ni cuestionó su representación virtual. Ello ocurrió porque la reforma requería el apoyo de los poderes territoriales. Como la historiografía ha ampliamente demostrado, el absolutismo, aún en Europa, no se consolidó en contra de la sociedad estamental, sino junto y gracias a ésta. En este sentido, el caso de Quito muestra como en el resultado de las reformas fueron fundamentales los grupos locales, ilustrando ello la interdependencia y las constantes interacciones entre autoridad estatal y poderes periféricos.

La revolución de los barrios que estalló en 1765 tras el intento, por parte del virrey de Santa Fe, Pedro Messía de la Cerda, de reformar la administración fiscal de Quito, constituye un interesante punto de partida a la hora de analizar las relaciones entre centro y periferia en la época del absolutismo ${ }^{5}$. La Audiencia de Quito representaba una de las principales fuentes de financiación para los puertos septentrionales de Nueva Granada, amenazados por la proximidad de las colonias inglesas de Jamaica y Curaçao. La recaudación de impuestos estaba en manos de recaudadores privados que se apropiaban de una parte considerable de los mismos a título de intereses y de reembolso de gastos. Para poner remedio a ello, el virrey decidió privar a la elite local del dominio de dos de lo sectores más importantes de la administración fiscal de la capital -aguardiente y alcabalas- y someterlos directamente al control de funcionarios españoles. Tales medidas, que casaban a la perfección con el ritmo de los tiempos y que correspondían a la voluntad de racionalización y de instauración de un control directo sobre el conjunto territorial de la Corona, tan común a la mayor parte de las monarquías de la época, si bien dieron lugar a un alto crecimiento de los ingresos del Estado, también supusieron una limitación importante de la autonomía local. En este sentido, la revuelta de los barrios de Quito tuvo una naturaleza esencialmente institu-

\footnotetext{
${ }^{4}$ Definición dada por Morse, 1972, p. 373.

${ }^{5}$ Mientras que la historiografía ecuatoriana tradicionalmente ha considerado dicha rebelión como un movimiento precursor de la independencia, algunos estudios más recientes, por el contrario, han subrayado que se trata de una verdadera revuelta antifiscal de antiguo régimen. Véase al respecto McFarlane, 1990 y ANDRIEn, 1990.
} 
cional. Se opuso a una determinada práctica política en lugar de al poder monárquico como tal, frente al que los rebeldes expresaron su lealtad.

Las nuevas medidas fiscales afectaron a toda la población de la ciudad, incluidos los sectores en situación más precaria. La insurrección estalló en los barrios de San Roque, San Sebastián y San Blas; parroquias en las que, en el límite entre el mundo rural y el urbano, vivían numerosos artesanos y pequeños comerciantes, por lo general agrupados en gremios o en corporaciones de oficios, de origen mestizo e indio. El levantamiento se extendió desde esas zonas marginales de la ciudad, que constituyeron el alma de la rebelión, hacia el centro, en donde fueron tomados al asalto los símbolos del reformismo borbónico: el negociado de impuestos y la destilería de aguardiente. El movimiento se radicalizó progresivamente hasta transformarse en verdadera rebelión con el ataque al palacio de la Audiencia, la destitución de sus jueces y el pillaje de las propiedades de los españoles. Sólo la intervención de la elite criolla y la constitución de un gobierno provisional, formado por representantes elegidos por los barrios, consiguió poner fin a la revuelta y restablecer el orden ${ }^{6}$, justo cuando los insurgentes, destruida ya la jerarquía política, comenzaban a amenazar el equilibrio social.

La rebelión demostró que a un funcionario enviado por Madrid no le era posible aplicar las reformas sin el sostén de los actores locales, los únicos en grado de allanar las tensiones sociales. Como consecuencia, su acción debía limitarse en lo sucesivo a un simple cálculo político, consistente en determinar la fórmula bajo la cual podía llevarse a cabo la parte esencial de las reformas -vale decir, las medidas fiscalessin lesionar las redes clientelistas locales. Paralelamente, la elite local, con la sola defensa de sus propios intereses, había demostrado su doble e irremplazable función de interlocutora del poder central y de garante del orden social. De ahí que, por mucho que este aspecto haya sido con frecuencia descuidado por los historiadores del periodo, tras la revuelta de 1765 se asiste a una colaboración cada vez más estrecha entre los funcionarios españoles y dicha elite ${ }^{7}$. Esta política de colaboración se consolidó bajo la presidencia de León y Pizarro, nombrado por Gálvez visitador general de la Audiencia de Quito, y encargado de poner en marcha el sistema de intendencias en la región. A consecuencia de la rebelión de 1765 y de las numerosas revueltas indígenas contra la introducción de nuevas medidas fiscales durante la década de 1760, León y Pizarro se vio obligado a negociar con las elites locales, y a sacrificar la reorganización administrativa y judicial del territorio a cambio de su apoyo a la reforma de los impuestos. El modo en que se redefinió el pacto entre poder central

${ }^{6}$ El gobierno provisional lo formaban, además de los diputados de los barrios, elegidos entre las familias más ricas de la ciudad, los representantes del cabildo, de la nobleza y del clero. Se nombraron asimismo "capitanes de barrios", a fin de proceder a su vigilancia y administración, mientras que se envió a misioneros jesuitas a las parroquias de Santa Bárbara, San Roque, San Blas y San Sebastián, al objeto de apaciguar a la población y restablecer el orden. McFarlane, 1990, pp. 238-239.

${ }^{7}$ La cuestión de las reformas borbónicas en Quito sigue sin ser objeto de estudios en profundidad, y algunos de sus aspectos, como el de la política institucional, no son considerados. Tan solo dos trabajos se han ocupado de la misma, el de TERÁn, 1988 y el de WASHBURn, 1984. No obstante, ambas obras olvidan remarcar la continua interacción existente entre los representantes del poder central y los del poder local, planteando la cuestión más bien en términos de oposición entre centro y periferia. 
y actores locales tras la revuelta de 1765 estuvo en el origen de notables cambios políticos en la región. El enfrentamiento entre la voluntad centralizadora de la Corona y las reivindicaciones locales condujo a una especie de compromiso: a cambio de una parcial renuncia a su dominio político en beneficio de las elites locales, la metrópoli obtuvo un sustancial aumento en sus ingresos fiscales. Las reformas borbónicas, pues, no llegaron a debilitar los cabildos, que, como veremos, conservaron sus jueces propios y ampliaron su influencia jurisdiccional sobre las zonas rurales 8 .

Durante este periodo se asistió a una verdadera reformulación de la relación contractual sobre la fiscalidad: a cambio del aumento de la recaudación fiscal, el Estado abandonaba una parte de sus prerrogativas en beneficio de la aristocracia local. Ahora bien, dicho intercambio en las competencias se materializó por medio de un pacto formal entre el presidente de la audiencia y el cabildo, lo que, de hecho, significaba el fracaso del proyecto de intendencias en la región. A pesar de la abolición de los corregidores, los intendentes y sus subalternos, los subdelegados, nunca fueron nombrados en Quito. Así las funciones jurisdiccionales de los primeros, y especialmente la jurisdicción sobre los indígenas, pasaron de hecho a los alcaldes ordinarios que de esta manera consolidaron sus poderes en el área rural. A causa del volumen de trabajo existente en el tribunal de la audiencia y de las dificultades técnicas presentadas por todo recurso en apelación, el poder jurisdiccional de primera instancia, ejercido en el interior de esferas políticas y sociales que escapaban parcial o totalmente a la autoridad del Estado, era de importancia estratégica en las sociedades del antiguo régimen. Para los alcaldes, que presidían el cabildo y pertenecían a las principales familias quiteñas, propietarias de haciendas y obrajes, fue un medio para reforzar su control sobre las tierras y la mano de obra indígena.

El caso de la Audiencia de Quito demuestra que, aun durante el reformismo borbónico, la Corona no logró imponer una mayor uniformidad y normatividad legal, sino que se limitó a aplicar selectivamente las normas según las circunstancias locales. El Estado incrementó los impuestos a cambio de una parcial abdicación de las funciones jurisdiccionales en las manos de la elite local. La consolidación de las prácticas de negociación de justicia a nivel local provocó, a su vez, la consolidación de las autonomías territoriales y corporativas y el asentamiento de una concepción plural de la soberanía, puesto que, en términos de mentalidad colectiva, el ejercicio de la soberanía seguía teniendo un carácter muy concreto: significaba administrar la justicia en todos los ámbitos de la vida social. Dado el fuerte vínculo entre justicia y soberanía en el antiguo régimen, la consolidación de los poderes jurisdiccionales de los cabildos durante la última fase de la época colonial resulta fundamental para comprender las dinámicas desencadenadas por la crisis monárquica de 1808 en los territorios de la Audiencia de Quito. Hay que subrayar, al respecto, que los cabildos de las ciudades principales jugaron un papel clave en la formación de las juntas autónomas de gobierno. Ausente el monarca, representaban los únicos cuerpos en grado de administrar el poder público por antonomasia: la justicia ${ }^{9}$. Como ha subrayado Antonio Annino, en la crisis de la monarquía hispánica, contrariamente a las demás

\footnotetext{
${ }^{8}$ Respecto a las consecuencias producidas por las reformas en el distrito de Quito véase MoreLLI, 1997, pp. 24-31.

${ }^{9}$ Sobre el protagonismo de los cabildos de las ciudades americanas durante la crisis de la monarquía, véase DYM, 2007b y VERDO, 2007.
} 
revoluciones atlánticas, el quid no fue tanto dónde se reubicó la soberanía con respecto a la representación, sino con respecto a la justicia ${ }^{10}$.

\section{LA JUSTICIA GADITANA: LA CONVIVENCIA DE ÓRDENES CONTRA- DICTORIOS}

El liberalismo constitucional español no cambió la trabazón entre municipios y justicia, porque la Constitución de 1812 no transformó la justicia del antiguo régimen en una de carácter moderno sometida al poder soberano. El dato es de fundamental importancia, no sólo porque la carta doceañista fue aplicada en muchos territorios de Ultramar, sino porque el constitucionalismo gaditano sirvió de modelo para el tema de la administración de la justicia en muchos de los países independientes.

Contra la opinión historiográfica de que el recurso de los constituyentes gaditanos al constitucionalismo histórico de la primera constitución española fue una maniobra política liberal, desde hace quince años, historiadores del derecho español han demostrado que tal referencia no fue simple táctica ni mera retórica ${ }^{11}$. La relación que quedó establecida entre las viejas leyes fundamentales y la nueva carta condicionó toda la obra legislativa de las Cortes, que estuvo inmersa en un debate jurídico acerca de la compatibilidad entre la constitución y las antiguas leyes de la monarquía. La primera consecuencia fue que, a pesar de la introducción de principios como la división de los poderes, la supremacía del legislativo y la subordinación del juez a la normativa de éste, no se cambió la administración de justicia, como queda establecido en el Discurso Preliminar:

Encargada por V.M. de arreglar un proyecto de Constitución para restablecer y mejorar la antigua ley fundamental de la Monarquía, se ha abstenido [la Comisión] de introducir una alteración sustancial en el modo de administrar la justicia, convencida de que reformas de esta trascendencia han de ser el fruto de la meditación, del examen más prolijo y detenido, único medio de preparar la opinión pública para que reciba sin violencia las grandes innovaciones ${ }^{12}$.

La comisión encargada de redactar el proyecto de constitución confesaba veladamente que novedad (la ley) y tradición (la justicia) podían yuxtaponerse, pero no subordinarse. De ahí la no introducción de novedad alguna en la práctica de jueces y tribunales, sobre todo en lo que concierne a un aspecto central de los regímenes constitucionales modernos fundados en la centralidad de la ley: la obligación de motivar las decisiones judiciales ${ }^{13}$.

\footnotetext{
${ }^{10}$ Annino, 2008.

11 Véase a este propósito Tomás y Valiente, 1995; Clavero - Portillo - Lorente, 2004; Garriga - LORENTE, 2007a.

12 Argüelles, 1981, p. 97.

13 Garriga - Lorente, 2007 b.
} 
La no motivación de las sentencias era una herencia del antiguo régimen derivada de que la incerteza jurídica que lo caracterizaba dificultaba enormemente que los jueces expresaran la causa (tal era la formulación corriente) de su decisión. Esto no implicaba que allí donde prevaleció la práctica de no motivar sentencias faltara cualquier tipo de garantía y reinase el más puro arbitrio; significa tan sólo que los particulares podían tener otras garantías distintas y más apropiadas a un derecho jurisprudencial y no legal como el ius commune. Así ocurrió en Castilla donde la práctica de no motivar las sentencias determinó desde la baja edad media la formación de un modelo jurisdiccional peculiar, que concentraba la garantía en la persona -y no en la decisión- del juez ${ }^{14}$. Al no prever la obligación de motivar las decisiones judiciales, en Cádiz el principio de vinculación del juez a la ley (expresado en el artículo 242) ${ }^{15}$ no se articuló con la garantía institucional correspondiente, limitando en la práctica la implantación de un régimen de legalidad. La sobrevivencia de esta antigua práctica en el nuevo orden constitucional nos muestra que en Cádiz no se rompió con el pasado. Al no tratar el constitucionalismo doceañista de proteger la ley frente a un juez/ intérprete -cuyo modelo remitía al de "juez perfecto" del antiguo régimen- y hacer la justicia coincidente con su persona y no con el silogismo normativo permanecía un modelo de administración de justicia dependiente de las "calidades" de los jueces.

El condicionamiento cultural que obligaba a los jueces a ganar la confianza de los justiciables llevó a los hombres de Cádiz a imaginar como ideal de justicia, al menos en la primera instancia, una justicia de iguales o, al menos, una justicia electa: la representada por los alcaldes. En Cádiz no se quitó la jurisdicción contenciosa a los alcaldes municipales, siendo el alcalde doceañista, como el alcalde ordinario del antiguo régimen, a un mismo tiempo administrador y juez. Aunque la Carta previó también la creación de jueces de primera instancia, los jueces letrados o de partido, la dificultosa restructuración del aparato de justicia, paralizada por la indivisión de partidos y por la escasez de letrados, necesitó de hecho a los alcaldes constitucionales. Con ello, en lugar de una justicia letrada y ajena a las corporaciones municipales, se asentó una justicia lega y electiva, vinculada a las mismas.

\section{LA CRISIS DEL TERRITORIO URBANO: LA MULTIPLICACIÓN DE LOS MUNICIPIOS}

Para comprender el papel desempeñado por los municipios hispanoamericanos durante el siglo XIX, a la no reforma del modelo de administración de justicia hay que añadir otro elemento clave: el modelo de autonomía territorial establecido por la Constitución de Cádiz. Una de las novedades más importantes introducidas por ésta fue la posibilidad para muchos pueblos de constituir sus propios ayuntamientos: el artículo 310 establecía que los pueblos con más de mil habitantes podían elegir sus municipios. La idea de los constituyentes era promover una amplia participación de

\footnotetext{
${ }^{14}$ Sobre esto véase Garriga, 1994.

15 "La potestad de aplicar las leyes en las causas civiles y criminales pertenece exclusivamente a los tribunales".
} 
los ciudadanos en la vida de los poderes públicos a nivel local para limitar la esfera de acción del poder ejecutivo. Entre 1812 y 1823, tanto en la región andina como en la mesoamericana, se constituyeron millares de ayuntamientos constitucionales ${ }^{16}$. Esto significó que muchos pueblos, incluso las comunidades indígenas, eligieron su propio municipio, rompiendo el dominio de las ciudades principales sobre los distritos rurales y provocando una verdadera revolución del poder local.

La idea del municipio moderno como contrapeso al poder del monarca había sido elaborada por los fisiócratas y plasmada en la Constitución francesa de 1791. Para la cultura de la ilustración, el poder municipal era un contrapeso al poder soberano y por lo tanto algo que antecedía la formación del Estado. De ahí que en la citada constitución, las communes y los officiers municipaux no se encuentren bajo el título III "Des pouvoirs publiques", sino en la parte que precede la configuración del aparato público: "Todo cuanto concierne a la cualidad de ciudadano, a la división del territorio o incluso a la organización de las asambleas primarias no forma parte de la constitución"; no son sino "supuestos anteriores al establecimiento público"17. Los constituyentes gaditanos retomaban esta idea cuando afirmaban que el objetivo de crear ayuntamientos y diputaciones era "establecer el justo equilibrio que debe haber entre la autoridad del gobierno, como responsable del orden público y de la seguridad del Estado, y la libertad de que no se puede privarse a los súbditos de una nación de promover por sí mismos el aumento y mejora de sus bienes y propiedades"18. Esta manera de concebir a los ayuntamientos, unida a la no división a nivel local entre justicia y administración, hizo que los municipios se convirtiesen en órganos soberanos, que se contraponían tanto al Estado central como a los cabildos de las ciudades provinciales. Como la justicia era todavía un atributo de la soberanía, ya que su ejercicio permitía intervenir en todos los ámbitos de la vida social, desde la defensa de los derechos y privilegios hasta la administración de los recursos y las cuestiones de gobierno, no son de extrañar que los pueblos justificasen la petición de elegir un ayuntamiento por la necesidad de administrar justicia ${ }^{19}$. Las investigaciones muestran que, en 1822 en el territorio de la Audiencia de Quito había unos 130 ayuntamientos constitucionales, cuando en 1812 los cabildos de españoles eran solamente doce ${ }^{20}$. Esto significa que muchos pueblos, e incluso las comunidades indígenas, habían ele-

16 Sobre la formación de los ayuntamientos constitucionales en los territorios americanos, cf. Annino, 1995, Chiaramonti, 2003, Morelli, 2005, Dym, 2007a, Ortíz Escamilla y Serrano Ortega, 2007.

${ }^{17}$ Sieyès, citado por MANNONI, 1994, p. 340.

${ }_{18}$ Proyecto de constitución política presentado a las Cortes generales y extraordinarias por su comisión de Constitución. Cádiz, Imp. Real, 1811, p. 5.

${ }^{19}$ Véase por ejemplo el caso de Guano (Riobamba): "El pueblo de Guano [....] tiene necesidad de este cabildo para la buena administración de justicia”. Comunicación dirigida al presidente Montes por varios vecinos de Guano solicitando se disponga el establecimiento del cabildo. Guano, 21-XII-1813. Archivo Nacional de Historia, Quito, [en adelante ANHQ] Fondo Especial, caja 196, lib. 483, doc. 152, fols. 142-143.

${ }^{20}$ Quito, Cuenca, Guayaquil, Ibarra, Otavalo, Ambato, Latacunga, Riobamba, Guaranda, Alausí, Loja, Portoviejo. Véase Morelli 2005, pp. 229-237. 
gido su propio municipio, rompiendo el dominio de las ciudades principales sobre los distritos rurales y provocando una verdadera revolución del poder local.

Para evaluar hasta qué punto la creación de los municipios en las áreas rurales quebró las jerarquías territoriales de la época colonial, hay que recurrir a dos tipos de fuentes: los documentos en los que los cabildos ciudadanos se oponían a la formación de municipios en los pueblos y los numerosos conflictos jurisdiccionales entre los alcaldes de las ciudades y los de los pueblos ${ }^{21}$. La creación de los ayuntamientos en éstos quitó a los cabildos citadinos una parte relevante de su poder jurisdiccional, sobre todo el que concernía a los conflictos sobre la tierra y la mano de obra indígena; con lo que la administración de los recursos y, sobre todo, de la justicia por parte de los pueblos rearticuló las relaciones entre ciudad y campo en favor del segundo. Así lo confirma el alcalde de Sangolquí (en el corregimiento de Quito), que oponiendóse a la intervención de los alcaldes de Quito en un asunto concerniente a la mano de obra indígena de una hacienda, reivindicó que su autoridad en materia de justicia no era en nada superior a la de su propio cabildo:

[...] no habiendose hecho o aprobado la distribución de partidos y nombradose por el gobierno los jueces de letras de los mismos, debo conocer de las causas civiles y criminales del mismo modo que V. con arreglo al art. $1^{\circ}$, cap. $4^{\circ}$ de la ley reglamentaria de 12 de oct. de 1812 y demás que precede, y por lo tanto aunque yo hubiese actuado alguna sumaria no le daría cuenta con ella por no corresponderle sino al juez de letras que se nombrase, en cuyo concepto y bien fundado podran estribar en lo sucesivo las determinaciones de V. que no es juez de apelación sino de primera instancia en la capital como lo soy yo en el distrito de este puelo y de ninguna suerte pedáneo como se titula ${ }^{22}$.

Si, por un lado, la expansión de los municipios en el área rural provocó una fragmentación del territorio; por el otro, favoreció la articulación de la sociedad local con el nuevo régimen liberal. Al determinar una amplia movilización política de los grupos locales, la experiencia liberal gaditana invita a repensar el liberalismo decimonónico como un régimen ni censal ni siquiera monoétnico. Resulta muy difícil comprender las dinámicas desencadenadas por la reforma municipal sin considerar que la carta gaditana permitió una base electoral muy amplia para la época. La ciudadanía no se definió a partir de la propiedad o de la fiscalidad, sino del concepto de "vecindad", que fue la antigua categoría de la tradición hispánica y que no excluyó ni a los

${ }^{21}$ Muy elocuente es al respecto la decisión del presidente de la Audiencia de Quito, el cual, interviniendo para solucionar el conflicto que oponía el municipio de Alausí al de Chunchi, un pueblo de su distrito, ordena al primero: “deberá proceder inmediatamente a la creación de cabildos constitucionales en todos los pueblos de aquella comprensión [...] en la inteligencia que el de aquel asiento no tiene, ni puede ejercer superioridad alguna sobre los de los pueblos, como que todos son independientes unos de otros". Oficio del presidente Don Melchor Aymerich al cabildo constitucional de Alausí. Quito, 22-I-1822. ANHQ, Fondo Especial, caja 238, lib. 593, doc. 12842. fol. 104.

${ }^{22}$ Oficio del alcalde constitucional de Sangolquí al alcalde de Quito. Quito, 1-III-1822. ANHQ. Notaría Primera, Caja 313, Exp. 28-II-1822. 
indígenas, ni a los analfabetos ${ }^{23}$. Además, como también han demostrado otros casos, las leyes electorales nunca dibujaron una ciudadanía verdaderamente individualista ni cortaron los lazos con las tradiciones, sino que fueron siempre muy flexibles, en el sentido de que dejaron arreglar muchos aspectos a las comunidades locales ${ }^{24}$.

La incorporación de los indígenas a la nueva ciudadanía liberal tuvo consecuencias fundamentales en lo concerniente a la cuestión municipal. Como ya se ha señalado, en América, el municipio colonial era una realidad compleja y pluriétnica, bien distinta de la ibérica, y esto acabó por modelar también la nueva representación. En las zonas indígenas, las reacciones fueron muy distintas según los lugares. Sin embargo, se percibe una tendencia común por parte de las comunidades, que utilizaron algunos mecanismos del nuevo sistema político para defender sus recursos y su identidad. Las Cortes de Cádiz habían proseguido la política anticorporativa del reformismo borbónico. La abolición de las repúblicas y de los cabildos de indios y su sustitución por el municipio, órgano que representaba todos los segmentos de la sociedad, así como los decretos para dividir las tierras comunales, respondían al objetivo de debilitar la estructura comunitaria y de transformar al indígena en ciudadano. Ocurrió sin embargo algo muy distinto: la participación masiva en las elecciones permitió a muchas comunidades articular las antiguas jerarquías internas con las nuevas jerarquías de los ayuntamientos electivos. No se trataba sólo de reproducir las tradicionales jerarquías indígenas dentro del contexto liberal, sino, sobre todo, de defender y reproducir los recursos materiales de las comunidades bajo la administración de las nuevas municipalidades. En efecto, tanto las tierras comunales como los otros recursos pasaron, en muchos casos, a los propios y arbitrios, que las Cortes habían atribuido a los nuevos ayuntamientos constitucionales. La representación liberal tuvo así el paradójico efecto de poner al amparo de los nuevos valores constitucionales los intereses organizados de la comunidad. El municipio liberal fue para los indígenas un instrumento para reconfirmar su propia autonomía y sus propios poderes sobre el territorio. Pero no sólo muchos cabildos de indios se transformaron en ayuntamientos constitucionales, sino que hubo una multiplicación general de las municipalidades, que a causa del vínculo estrecho entre justicia y administración, causó una multiplicación de jueces locales.

\section{LA GUERRA SOCIALIZADA: PUEBLOS Y MILICIAS}

La ampliación de la justicia lega en el territorio de la audiencia no solo resultó de la aplicación del liberalismo gaditano, sino también de las guerras que afectaron el territorio de la Audiencia entre 1809 y 1812 y entre 1820 y 1822 . Como muchos estudios han demostrado, es muy difícil entender el papel desempeñado por las milicias y el ejército en las guerras de independencia sin considerar las reformas militares de la época borbónica ${ }^{25}$. Aunque el proceso de militarización de los territorios americanos

\footnotetext{
${ }^{23}$ AnNino, 1994, p. 244.

24 Véase a este respecto Romanelli, 1998, Gueniffey, 1993.

25 Archer, 1983, Marchena Fernández, 1992, Ortiz Escamilla, 1997, Thibaud, 2003.
} 
mediante milicias, produjo ciertos resultados que parecían contradecir la política de centralización y reducción de las autonomías locales y corporativas emprendida por los Borbones, como fueron el refuerzo de la autoridad de los cuerpos territoriales tradicionales, el acceso de los criollos a nuevos cargos y una extensión de los privilegios (el fuero militar) a nuevos segmentos de la sociedad, ello estaba previsto por el mismo modelo ilustrado. Además de motivos estrictamente estratégicos y fiscales, había también razones de tipo teórico a favor de dicho sistema de defensa, razones vinculadas a las nuevas ideas de ciudadanía y de patria elaboradas por los mismos ilustrados. En su imaginario político cuatro obligaciones -con Dios, el rey, la patria y con uno mismo- debían guiar la actuación del ciudadano, permitiéndole atender la exigencia de las dos repúblicas que estaban a su cargo, la de su familia y la de su Pueblo, desempeñando a la vez el papel de "Padre de Familia" y el de "Republicano"26. En este sentido, la creación de milicias no constituía sólo un instrumento militar de defensa, sino también un medio para reforzar los deberes del ciudadano hacia la patria y el monarca, para exaltar "el amor a la patria".

La idea de que el modelo de milicias, respecto al de los ejércitos regulares, fuese más útil al desarrollo de la sociedad y del Estado pertenecía a la cultura ilustrada de aquella época y tenía una naturaleza fisiocrática: los ejércitos permanentes, al obligar a muchos jóvenes a permanecer en celibato, representaban un grave obstáculo al crecimiento demográfico de la población, sustrayendo, además, muchos brazos a la agricultura. En favor de las milicias actuaba también la general desconfianza de los ilustrados respecto de los ejércitos como medio para conservar la paz y la tranquilidad interna de los Estados: como demostraban múltiples ejemplos de la historia, éstos representaban más bien un factor de inestabilidad para los gobiernos y de opresión para los pueblos. El debate que se abrió en torno a los años a 1780 sobre el papel de las "milicias provinciales" españolas puede ayudar a comprender los términos de la cuestión en el caso más específico de América. Tanto el dictamen de Aranda como el cuestionamiento de O'Really originaron un modelo de milicias menos dependientes del control de los inspectores del ejército y de los oficiales del rey y más vinculados a los sujetos territoriales locales (justicias de los pueblos, hacendados, cabildos) ${ }^{27}$. El tipo de unidad defensiva que se instauró en ultramar al final del siglo XVIII fue, por estos motivos, más próximo a las milicias republicanas que a las disciplinadas. Estas últimas hubieran necesitado de la presencia de veteranos que en realidad no hubo sino en las zonas costeñas más amenazadas por los ingleses. No se trataba, por tanto, de una degeneración del modelo militar europeo, aplicado en un contexto político y cultural inadaptable a las ideas liberales, sino más bien de la aplicación del mismo. El modelo de milicias de la época ilustrada remitía a una tradición republicana que, desde el principio del siglo XVIII, había sido utilizada principalmente con una función antidespótica. Se planteaba la construcción de un nuevo republicanismo, capaz de conciliar las virtudes antiguas con la participación de los más en la cosa pública. Las milicias y el modelo de ciudadano-soldado debían responder a este mismo

\footnotetext{
26 Fernández Albadalejo, 2001, p. 528.

${ }^{27}$ Oñate Algueró, 2003, pp. 156-157.
} 
fin: la participación en el sistema defensivo reforzaría el amor de los milicianos a la patria, entendida como comunidad política de hombres iguales. El resultado no fue necesariamente ese, no sólo porque para hacer funcionar el sistema se recurrió a las elites locales y a la entrega de privilegios, sino también porque en el mundo hispánico la patria no correspondía, como hubiera requerido el nuevo concepto de "nación en armas", a una comunidad política amplia, sino al lugar de origen, a la patria chica, a los pueblos, provincias y ciudades.

El modelo ilustrado de milicia contenía muchas de las características que serán propias de los sistemas defensivos liberales del siglo XIX. La Constitución de Cádiz o las primeras constituciones de los países hispanoamericanos refrendaban un sistema muy similar al establecido por los Borbones en la segunda mitad del siglo XVIII: al lado de un ejército regular se preveían normalmente unas milicias nacionales, organizadas en cada provincia en función de su número de habitantes, siendo confirmados el fuero y la organización local de las mismas. Había, sin embargo, una diferencia notable a nivel normativo, que tenía que ver con una de las novedades más significativas de la modernidad: la representación política liberal. Ello hacía que tanto en el sistema constitucional gaditano como en las constituciones republicanas los oficiales de las milicias debiesen ser elegidos democráticamente por todos los miembros de las mismas ${ }^{28}$. Las razones tanto prácticas como más esencialmente políticas que sostenían el sistema defensivo miliciano eran: la falta de dinero, la necesidad de movilizar a la población frente a las guerras o la creación de un vínculo político y aún afectivo con la nación. Pero fue fundamentalmente la función político-social de la milicia, en virtud de la cual la subordinación de la tropa a un oficial uniformado favorecía igualmente la subordinación social al mismo hombre notable cuando éste no portaba uniforme, lo que empujó a los constituyentes de uno y otro lado del Atlántico a decantarse por ese modelo. De hecho, la participación en las milicias, al igual que la participación en el voto, permitía reconciliar el concepto de soberanía popular o nacional con la supervivencia de una estructura social jerárquica. De ahí que se sostenga que el método electivo de la oficialidad de la milicia no transformase el peso del rango, sino, al contrario, reforzara su función a la vez política y social. El voto permitió que los notables locales gozaran de una doble legitimidad: éstos no sólo resultaban electos para los cargos civiles, sino también para los militares. A causa de esta coincidencia, a menudo se creó a nivel local una doble jurisdicción: los alcaldes y regidores -que según los sistemas constitucionales debían ser electos- con frecuencia eran también oficiales en las milicias locales. El simultáneo ejercicio de cargos judiciales y militares por los mismos individuos comportó no sólo un refuerzo de su poder personal en el seno de las comunidades, sino también una mayor autonomía de éstas en relación al Estado.

El vínculo entre militarización, representación y justicia se hizo aún más evidente a causa de las guerras. Tanto en las zonas rebeldes como en las controladas por los realistas, el mando, la organización y la financiación de las milicias pasó completa-

${ }^{28}$ Véase, por ejemplo, Reglamento para la milicia nacional. Madrid, 15-IV-1814. En Colección de los decretos y órdenes que han expedido las Cortes ordinarias desde 25 de Septiembre de 1813 hasta 11 de Mayo de 1814, t. V, Madrid, 1822, pp. 168-169. 
mente a las instituciones representativas locales. El alto grado de fragmentación territorial producido por las guerras y la institución de los ayuntamientos constitucionales en las áreas rurales sustrajo al Estado todo tipo de poder sobre esos cuerpos militares, que pasaron por entero a estar bajo control de los órganos electivos locales. Los milicianos se identificaban más bien con sus comunidades territoriales, cuyos oficiales eran los representantes naturales. Entre 1820 y 1822, el mencionado vínculo entre militarización, representación y justicia se hizo aún más evidente, ya que las milicias pasaron no sólo de hecho, sino también de derecho, a ser controladas por los municipios constitucionales: el mando, la organización y la financiación de las milicias pasó de las autoridades militares a las instituciones representativas locales. Así, un decreto de las Cortes fechado en 1820 establecía que los ayuntamientos se encargarían en lo sucesivo de organizar las elecciones de los oficiales militares, que debían ser elegidos por los soldados por mayoría absoluta y ante la asamblea municipal; de proveer a su mantenimiento gracias al fondo de los propios y arbitrios; $y$, finalmente, de tomar las decisiones, en acuerdo con el jefe político, en todas las operaciones militares ${ }^{29}$. El nexo formal entre municipios y milicias comportó dos tipos de consecuencias. En primer lugar, la elección directa de los oficiales consolidó la relación entre justicia y poder militar, ya que la elección a menudo recaía en individuos que, merced a su prestigio y su notoriedad, ejercían ya funciones jurisdiccionales. El hecho de gozar de una doble legitimación popular reforzaba aún más su autoridad personal sobre la comunidad local. En segundo lugar, el control financiero y organizativo de los ayuntamientos sobre las milicias terminó causando la derrota de los realistas. El aumento de las contribuciones impuestas por las autoridades españolas a las comunidades a fin de sostener el esfuerzo militar provocó una reacción negativa de las mismas. Éstas, al contar con los poderes de los municipios, se negaron a pagar impuestos y a suministrar tropas a los realistas. La recaudación fiscal en los pueblos se tornó casi imposible, como lo demuestran los fracasos sufridos por los municipios de Quito y Cuenca cuando intentaron enviar delegados a los pueblos para reclutar hombres o requisar animales. La negativa de los alcaldes, en nombre de los pueblos, a conceder la más pequeña contribución ${ }^{30}$, generó una fuerte crisis financiera en el seno de las tropas realistas.

Después de batalla de Pichincha, en 1822, la audiencia pasó a formar parte de la Gran Colombia. Las leyes de nueva república confirmaron, sin embargo, el fuero militar, que contrariamente a otros privilegios del antiguo régimen, permaneció en vigor. Asimismo, a imitación del modelo de Cádiz, otorgaron a las municipalidades un papel central en la formación de las milicias, cuyo reclutamiento debía basarse en listas preparadas por ellas, debiendo celebrarse la elección de los oficiales en presencia del consejo municipal del cantón ${ }^{31}$. Ello demuestra que, aun lograda la inde-

${ }^{29}$ Artículos 27, 32, 71 del Reglamento provisional para la milicia nacional en las provincias de Ultramar. Madrid, 24-X-1820. ANHQ, Milicias, caja 7, exp. 24-X-1820.

${ }^{30}$ Para el caso de Quito, cf. ANHQ, Fondo Especial, caja 242, lib. 604, doc. 12.918; para el de Cuenca, cf. Archivo Histórico Municipal de Cuenca, Actas de Cabildo, 1821-1825.

${ }^{31}$ Artículos 6 y 44 de la "Ley orgánica de la milicia nacional", Gaceta de Colombia, suplemento del n² 240. Bogotá, 11-V-1826. 
pendencia, el poder militar no fue controlado exclusivamente por el Estado y que la sociedad local continuó jugando un papel preponderante en la organización de las fuerzas armadas. Esa anomalía fue subrayada por la Gaceta de Colombia, el órgano de prensa gubernamental, que en un artículo sobre la milicia nacional criticó no sólo el sistema de elección de los oficiales (elegidos por mayoría absoluta por los soldados de cada cuerpo), sino sobre todo la intervención de las municipalidades en la organización de tales tropas, sirviéndose de una comparación con las constituciones de los Estados norteamericanos:

En lo que están de acuerdo todas las constituciones [de los Estados norteamericanos] es en no dar parte ni intervención alguna a las municipalidades en cosas de la milicia, en reservar al gobernador del estado, en calidad de poder ejecutivo la facultad de aprobar y despachar las patentes oficiales, y en quitarle toda clase de intervención cuando las milicias son llamadas al servicio por el gobierno general de la unión ${ }^{32}$.

Era muy difícil privar de tales atribuciones a las municipalidades para entregárselas a los agentes del poder ejecutivo, como lo sugería el autor del artículo, pues dichas instituciones eran las únicas en grado de ejercer un control directo sobre el territorio y establecer las listas de reclutamiento.

La supervivencia de semejante modelo de defensa dio a las autoridades judiciales la posibilidad de continuar disponiendo de un doble poder jurisdiccional, lo que consolidó la autonomía de la justicia a nivel local. Ese entrelazamiento entre jurisdicción civil y militar reforzó ante todo el poder de los alcaldes municipales, como lo afirmaba el gobernador de la provincia de Esmeraldas al intendente del departamento:

[...] me expongo a sufrir los mayores desaires y bochornos, pues como están afianzados [los alcaldes municipales] con las armas pueden hacer y obrar como les dé la gana, pues así lo estoy experimentando ${ }^{33}$.

Además del poder de los alcaldes municipales, esa doble jurisdicción consolidó igualmente el de las autoridades inferiores como los alcaldes parroquiales ${ }^{34}$. Según las leyes, la milicia nacional se componía de las milicias "auxiliares", formadas a nivel cantonal, y las "cívicas", reclutadas en pueblos y ciudades ${ }^{35}$. Los municipios cantonales, en las ciudades, y las juntas parroquiales, en los pueblos, tenían por tarea redactar las listas de reclutamiento. Las juntas parroquiales, compuestas por dos alcaldes, un procurador síndico y dos vecinos del pueblo, tenían también el deber de

\footnotetext{
32 "Milicia nacional", Gaceta de Colombia, no 171, 23-I-1825.

${ }^{33}$ Denuncia de Vicente Chiriboga gobernador político de la provincia de Esmeraldas al intendente del departamento, José Félix Valdivieso, contra el comandante y alcalde de este cabildo. Esmeralda, 24-VIII-1824. AHN/Q, Fondo Especial, caja 250, lib. 620, doc. 52.

${ }^{34}$ A este propósito, notemos que el nuevo régimen colombiano había abolido una buena parte de los municipios de la época de Cádiz, y que a pesar de eso en cada pueblo el poder jurisdiccional de los alcaldes parroquiales siguió siendo considerable. MorelLi, 2005, pp. 240-246.

35 "Ley orgánica de la milicia nacional” (30-III-1826), Gaceta de Colombia, nº 240, 21-V-1826.
} 
presidir la nominación de los oficiales, elegidos por los miembros de cada cuerpo ${ }^{36}$. Pero los alcaldes parroquiales no se contentaban con presidir las elecciones, sino que intervenían directamente en la elección de los oficiales, haciéndose elegir ellos mismos o imponiendo su candidato a la tropa ${ }^{37}$.

Lejos de limitarlo, el gobierno de la Gran Colombia reforzó el fuero militar. Una circular de 1828 determinó que cada cuerpo del ejército debía establecer un consejo, compuesto por siete oficiales, destinado a juzgar todos los delitos cometidos por los militares $^{38}$. Esa doble jurisdicción favoreció poco después la fuerza de los caudillos del siglo XIX, cuyo poder, administrado hasta entonces de manera esencialmente jurisdiccional, no derivó en efecto de las armas, sino más bien del fuero militar y de las prácticas judiciales. Además ese fue también el único modo de convencer a las comunidades locales para que apoyaran el esfuerzo de la guerra, según lo confirma uno de los artículos de las instrucciones de la ciudad de Portoviejo a su diputado al Congreso constituyente de 1829:

[...] es muy conveniente se declare expresamente la continuación del goce de los fueros militar y eclesiástico, cuyas fuerzas básicas e influjo moral, han sido en todo tiempo el apoyo de los gobiernos, y cuya privación acarrearía al Estado males incalculables $^{39}$.

En dicho texto, el ayuntamiento de Portoviejo declaraba abiertamente que la concesión de los privilegios de antiguo régimen y de autonomías era para el gobierno un modo de asegurarse el apoyo de las sociedades locales.

Debido al poder de las comunidades locales, que organizaban las milicias, gozaban del fuero y controlaban además las armas, los caudillos no pudieron prescindir de su apoyo en la conquista de una provincia o de un Estado. Así, esa tan discutida forma de poder fundaba localmente su legitimidad a un tiempo sobre la idea de soberanía de los pueblos y sobre las prácticas de justicia a nivel local. La revuelta de Chiguaguas, por ejemplo, que estragó la provincia de Guayaquil durante tres años, tuvo como protagonistas tanto a los caudillos como a los pueblos ${ }^{40}$. Tras cada facción armada conducida por un caudillo, como Bravo, Hidalgo, Navas u Osés, se movía una pequeña sociedad que se movilizaba con todo tipo de armas; lo que comportó una consolidación de los vínculos de lealtad personal entre los jefes militares y las comunidades contra las autoridades centrales y favoreció el proceso de autonomización de los pueblos.

\footnotetext{
${ }^{36}$ Ibídem, arts. 6 y 55

${ }^{37}$ A menudo las elecciones tenían lugar por unanimidad de votos, como si hubiese existido un acuerdo previo entre los milicianos y la junta. Elección de los oficiales de la milicia cívica del pueblo de Cotacachi. Cotacachi, 21-I-1827. ANHQ, Fondo Especial, caja 256, lib. 636, doc. 88.

38 "Reglamento para conocer y determinar las causas militares". El colombiano del Guayas, n" 61, 12-XII-1828.

39 "El voto de Manabí o instrucciones que ha de observar el señor diputado al congreso constituyente". Portoviejo, 29-IX-1829. Gaceta de Colombia, n 446, 3-I-1830.

${ }^{40}$ La revuelta estalló en el mes de octubre de 1833 a causa de la insurrección de las tropas de Guayaquil contra el gobierno de Flores.
} 
Las guerras y la expansión del fuero que éstas determinaron produjeron, junto al incremento del número de municipios, una multiplicación de autoridades jurisdiccionales en el territorio. El resultado de este proceso fue que de la confianza se pasó progresivamente a las armas, en el sentido de que los que ganaban la elección de alcaldes o tenientes eran cada vez más los oficiales de milicias, o sea, los que manejaban armas. Esto produjo en el largo plazo una desconfianza de los ciudadanos en las elecciones de los jueces locales, porque con frecuencia ya no se respetaban aquellas calidades que tradicionalmente habían asegurado la confianza en las personas. De ahí las protestas, más numerosas a partir de la década de 1830, contra la presencia de los milicianos o militares en las elecciones municipales. Por ejemplo, los ciudadanos del pueblo de Riofrío, en la provincia de Guayaquil, pedían que "se hagan retirar los jefes y oficiales que se apoderan diariamente de las mesas eleccionarias, pues hemos visto que se mantienen en ellas para hacer sufragar a los subalternos que, con solo la presencia de sus jefes ya no tienen voluntad propia porque la subordinación que les impone la ordenanza los hace aparecer ciegos instrumentos del que los manda, y este solo hecho manifiesta coacción, fuerza y violencia"41.

La justicia no contribuyó, por lo tanto, al proceso de institucionalización del Estado, ya que no se construyó una administración de carácter comisarial, jerarquizada para la ejecución imparcial de la ley (según el modelo francés), sino que articuló toda una serie de autoridades muy diversas por su origen y naturaleza. En la mayoría de los estados del mundo hispano el escalón inferior de la justicia estuvo poblado por jueces legos. Aunque esto fue en parte el resultado de la insuficiencia de letrados y de la falta de fondos, el simple hecho de que la justicia local fuera dejada en manos de alcaldes legos lleva al historiador a peguntarse hasta qué punto cabe hablar de un modelo de juez sometido a la ley. Dado que en muchos países americanos no fue establecido, como en el caso gaditano, un principio de responsabilidad legal - o sea la obligación de motivar las sentencias- la esfera de discrecionalidad de los jueces siguió a lo largo de la época republicana. Finalmente, la imposible transformación de un modelo jurisprudencial de administración de la justicia en uno sometido a la ley obligó a que las garantías del proceso se fiasen por entero a la articulación del régimen de responsabilidad personal de los jueces.

El hecho de que las guerras y el modelo de milicias nacionales hayan creado en muchos casos una doble jurisdicción - civil y militar- a nivel local, a lo largo, ha puesto en cuestión el antiguo sistema de jurisdicción que se basaba fundamentalmente en la confianza de las comunidades locales en la persona del juez. A la confianza se yuxtaponen, y en algunos casos, se sobreponen las armas. Cuando los dos poderes - civil y militar- coincidían y eran en todo caso la expresión de las sociedades locales, la confianza en la recta y pronta administración de justicia dependía todavía de las "calidades" de las personas, reconocidas por la comunidad a través de la elección. Cuando, sin embargo, los dos poderes no se correspondían y las autori-

\footnotetext{
41 "Relación del movimiento de militares para obtener el triunfo de las elecciones en las parroquias". Guayaquil, 22-X-1850. Biblioteca Aurelio Espinosa Polit, Cotocollao. Quito. Impresos 18461850.
} 
dades militares procedían de otro ámbito territorial o de poder, el modelo tradicional jurisprudencial entraba en crisis.

Dado que la justicia significaba todavía la capacidad de imponer comportamientos coactivamente, de dictar normas generales y particulares, de resolver contenciosos entre parte, de perseguir y castigar las transgresiones al orden y de mantener a cada uno en su derecho, no se podía no considerar peligroso atribuirla a unas autoridades procedentes de afuera o nombradas por poderes superiores.

\section{REFERENCIAS BIBLIOGRÁFICAS}

ANDRIEN, Kenneth

1990 "Economic Crisis, Taxes and Quito Insurrection of 1765". Past and Present. Oxford. $\mathrm{n}^{\circ}$ 129, pp. 104-131.

AnNINO, Antonio

1994 "Soberanías en lucha". En Annino, Antonio; Castro-Leiva, Luis y GueRRA, François-Xavier. De los imperios a las naciones: Iberoamérica. Zaragoza. IberCaja, pp. 229-253.

1995 "Cádiz y la revolución de los pueblos mexicanos, 1812-1821". En ANNINO, Antonio (dir.). Historia de las elecciones en Iberoamérica, siglo XIX. Buenos Aires. Fondo de Cultura Económica, pp. 177-226.

2008 "La ruralización de la ciudadanía durante la crisis de la monarquía hispánica". Seminario de Doctorado de la Universidad de Paris I "Ecrire l'histoire de l'Amérique Latine contemporaine", coordinado por Annick Lempérière. Paris. (Inédito)

ARCHER, Christon

1983 El ejército en el México borbón, 1760-1810. México. Fondo de Cultura Económica.

Argüelles, Augustín de

1981 Discurso preliminar a la Constitución de 1812. Edición de Luis Sánchez Agesta. Madrid. Iter.

Chiaramonti, Gabriella

2003 Suffragio e rappresentanza nel Perù dell'800. Gli itinerari della sovranità (1808-1860). Torino. Otto.

Clavero, Bartolomé - Portillo, José María - Lorente, Marta

2004 Pueblos, Nación, Constitución (en torno a 1812). Vitoria. Ikusager Ediciones. 
DyM, Jordana

2007a From Sovereign Villages to National States. City, State and Federation in Central America, 1759-1839. Albuquerque. University of New Mexico Press.

2007b "Soberanía transitiva y adhesión condicional: lealtad e insurrección en el Reino de Guatemala". Araucaria. Revista Iberoamericana de Filosofía, Política y Humanidades. Chihuahua. no 18, pp. 196-219.

FARRIS, Nancy

1984 Maya Society under Colonial Rule: the collective enterprise of survival. Princeton. Princeton University Press.

Fernández Albadalejo, Pablo

2001 "Dinastía y comunidad política: el momento de la patria". En FERNÁNDEZ Albadalejo, Pablo (ed.). Los Borbones. Dinastía y memoria de nación en la España del siglo XVIII. Madrid. Marcial Pons. pp. 485-532.

Garriga, Carlos

1994 Las Audiencias y las Chancillerías castellanas (1371-1525). Historia política, régimen jurídico y práctica institucional. Madrid. Centro de Estudios Políticos y Constitucionales.

Garriga, Carlos y Lorente, Marta

2007a Cádiz 1812. La constitución jurisdiccional. Madrid. Centro de Estudios Políticos y Constitucionales.

2007b "El juez y la ley: la motivación de las sentencias". En GARRIGa y LoRENTE, 2007a, pp. 261-312.

GuENIFFEY, Patrice

1993 Le nombre et la raison. La Révolution française et les élections. Paris. Editions de l'EHESS.

MANNONi, Stefano

1994 Une et indivisible. Storia dell'accentramento amministrativo in Francia. Milano. Giuffré.

Marchena Fernández, Juan

1992 Ejército y milicias en el mundo colonial americano. Madrid. Mapfre.

McFarlane, Anthony

1990 "The Rebellion of The Barrios". En Fisher, John; Kuethe, Allan y McFarlane, Anthony (eds.). Reform and Insurrection in Bourbon New Granada and Peru. Baton Rouge. Louisiana State University Press, pp. 197-254. 
MoRelLi, Federica

1997 "Las reformas de Quito. La redistribución del poder y la consolidación de la jurisdicción municipal". Jahrbuch für die Geschichte vom Staat, Wirtschaft und Gesellschaft Latinamerikas. Köln. $\mathrm{n}^{\circ}$ 34, pp. 183-207

2005 Territorio o Nación. Reforma y disolución del espacio imperial en Ecuador, 1765-1830. Madrid. Centro de Estudios Políticos y Constitucionales.

MORSE, Richard M.

1972 "A prolegomenon to Latin American Urban History". Hispanic American Historical Review. Durham. n 52:3, pp. 359-394.

Oñate Algueró, Paloma de

2003 Servir al Rey: la milicia provincial (1734-1846). Madrid. Ministerio de Defensa.

Ortiz Escamilla, Juan

1997 Guerra y gobierno. Los pueblos y la independencia de México. Sevilla. Universidad de Sevilla/Universidad Internacional de Andalucía/ El Colegio de México/Instituto Mora.

Ortiz Escamilla, Juan y Serrano Ortega, José Antonio

2007 Ayuntamientos y liberalismo gaditano en México. Zamora. El Colegio de Michoacán-Universidad Veracruzana.

Poloni-Simard, Jacques

2000 La mosaïque indienne. Mobilité, stratification sociale et métissage dans le corregimiento de Cuenca (Equateur) du XVI au XVIII siècle. Paris. Editions de l'EHESS.

RomANELLI, Raffaele (ed.)

1998 How did they become voters? The history of Franchise in Modern European Representation. The Hagne. Kluwer Law International.

TERÁn, Rosemarie

1988 Los proyectos del imperio borbónico en la Real Audiencia. Quito. Abya Yala.

ThiBAud, Clément

2003 Repúblicas en armas. Los ejércitos bolivarianos en la Guerra de Independencia en Colombia y Venezuela. Bogotá. Planeta.

Tomás y VAliente, Francisco

1995 "Génesis de la Constitución de 1812. De muchas Leyes Fundamentales a una sola Constitución”. Anuario de Historia del Derecho Español. Madrid. tomo LXV, pp. 13-126. 
VERDO, Geneviève

2007 "La ciudad como actor. Prácticas políticas y estrategias de pertenencia: el caso de Río de la Plata (1810-1820)". Araucaria. Revista Iberoamericana de Filosofía, Política y Humanidades. Chihuahua. no 18, pp. 116285.

WASHBURn, Douglas A.

1984 The Bourbon Reforms: a Social and Economic History of the Audience of Quito, 1760-1810. Ph. D. University of Texas. Austin. 